\title{
Design of Modern Hotels - Humanization of the Residential Environment
}

\author{
Elzbieta Trocka-Leszczynska and Joanna Jablonska \\ Faculty of Architecture, Wroclaw University of Technology, Poland \\ \{elzbieta.trocka-leszczynska, joanna.jablonska\}@pwr.wroc.pl
}

\begin{abstract}
After the hotel building boom before Euro 2012, the Polish tourist branch is currently experiencing a period of stabilization. Current investments are prepared with more consideration as regards the ways of gaining and attracting new customers to the proposed services. Small and very economical buildings like hostels and motels that are erected nowadays are attracting a young part of the society, while elegant and more expensive buildings gain customers from constantly aging people. Attempts to provide better and well-adjusted functions evolve along the demand to meet different needs of people with various disabilities. Humanization and individualization of service for the benefit of various customers should be based on appropriate ergonomic solutions and novel technologies. Analyses will be carried out on recommendations for hotels designed for people with disabilities, different medical conditions and representative case studies of German examples.
\end{abstract}

Keywords: ergonomics in architecture, hotels for the disabled, hotels for the elderly, ergonomics of the disabled.

\section{Introduction}

The Polish hotel branch has gone through significant changes during the last five years. Transformations started with the announcement of the list of countries organizing Euro 2012 and many investors noticed this as an opportunity to expand their capital. Buildings with a variety of residential opportunities were put up within a short period of time without much thought about long-term policies and their future functioning. A process of decreasing birth rate, which is generally observed in Europe, combined with a constant increase of longevity together with very active lifestyles of the elderly contribute to the creation of a new type of a hotel user. This person is more demanding and may suffer from usually minor disabilities, however at the same time such customers are also able to pay larger amounts of money for their comfort and realization of needs than young globetrotters. The elderly not only travel in order to deepen their knowledge, but also to use a hotel as a place for doing business or as a target leisure, relaxation or beauty centre. Along with a need to provide perfectly suited environment and functions, there evolves a demand for adjusting services to various disabilities such as vision and hearing disorders, movement dysfunctions or disorientations. In the light of these assumptions, it seems necessary that a modern 
hotel design should be focused not only on providing original interiors with technological novelties, but also on humanization and individualization of the public and private space in order to improve safety and well-being of users.

\subsection{Purpose and Method of Research}

The main purpose of the paper was to study a current state of knowledge on modern hotels and solutions implemented in working units in order to establish possible adjustments and amenities for the elderly and people with various physical and mental disabilities and dysfunctions. Attention was focused not only on major problems but also on minor disorders that impede and lower the comfort of a stay beyond a usual dwelling place on a temporary basis because it may affect any member of the population. All these solutions were compared with anthropometric human features and equipment measurements in order to describe the best suited standards. The literature studies were carried out on a number of examples and already existing recommendations. They were analyzed in the light of case studies researched in the form of field studies in Windmühle Seifhennersdorf - a complex including workshops, a hotel and green surroundings adapted for the needs of people with disabilities. A detailed focus was on components such as the main hall and reception hall, public horizontal and vertical communication, rooms with bathrooms and sports and leisure zones as they are closely connected with guest service and their design has a direct influence on the customers' comfort. An ergonomic and aesthetic standard of those spaces is constantly changing due to the development of new building and industrial technologies, materials, human expectations and a need for concurrency. The main methods used in the presented studies were graphical, comparative analysis, case and literature studies as well as field studies along with a synthesis.

\section{Discussion - Hotels in Poland}

In Poland in the 1970s the problem of architectural adjustment was widely harnessed by the legislation system and later in the 1980s it was described in technical conditions for buildings. However, realizations of these times did not take into account the suggested solutions. [1, p. 11] This situation has significantly changed and nowadays the problem of the disabled in architecture is widely recognized and discussed. In the case of hotels, however, solutions are limited to one or two adjusted units while the rest of the design is subordinate to aesthetical design. Lobbies, restaurants, sport areas, bars, clubs and cafes are usually planned as if they were meant only for fully healthy people. Complicated spatial plans, 'designer' solutions and sophisticated technological equipment can create hazards to all users. An important part of discussion is to define who should be included in a group with disabilities and what activities should be expected. Błądek [2, p. 19] elaborated a list of incapacities that each hotel should be prepared for, e.g. movement supported with different medical devices such as canes, crutches, balconies, wheelchairs, prosthesis, the blind and visually impaired, the deaf and hard of hearing, temporary manual, movement or perception disorders, allergies, phobias typical of the elderly, children strollers, pregnant women 
and others. According to the statistical data presented in 'National Census of Population and Housing 2011. Report of the results' of Polish Central Statistical Office (Pol. Główny Urząd Statystyczny GUS) for the year 2011 (initial result), 12,2\% of the population suffers from different forms of disability. The responders voluntarily declared or presented a valid document confirming their health status, which allows us to believe that this data is yet underestimated. [3, pp. 64] The overall number of people with dysfunctions, elderly and persons with temporary incapability reaches $30 \%$ and is similar to other European countries. [1, p. 13]

There are several general references that can be used for each hotel design. Cars and buses should be able to drive up directly to the front of the main entrance. The surface of the driveway must be hard, even and leveled with the interior floor. If a threshold is necessary it cannot be higher than $0,02 \mathrm{~cm}$. Available space should be sufficient for wheelchair accommodation, an accompanying person and free passage for other users. It must be remembered that the minimum operational space for a person on a wheelchair is set at $150 \times 150 \mathrm{~cm}$ and must be provided in front of any doors, slopes, stairs, etc. In the interiors it is crucial to keep the main communication path clear of permanent impediments and movable items that could block movement or create hazards. Lack of level changes or thresholds is advisable as well as avoidance of intersections between transportation and service paths with movement of people. A clear, understandable spatial layout with significant landmarks and without small vestibules, sluices or unnecessary door multiplication should be designed. The main entrance ought to be leading into the hall with information and reception that is clearly marked and contain places for service of people on wheelchairs. Surfaces of desks and tables ought to be placed on a certain height and have width that can be reached from a wheelchair or by a person who uses a cane (for the usually elevated reception desks the recommended height is $90 \mathrm{~cm})$. [2, pp. 21-22, 53-54, 4, pp. 46, 5, p. 27, 6, p. 40]

Form and arrangement of furniture, appliances and utensils must be safe for all users and rounded angles are recommended. Due to a number of different disabilities and their character, workplaces should be adapted to individual needs. All movement areas and work surfaces ought to be well lit with light of constant frequency, providing proper color perception. It is also important that monochromatic colors and uniform textures for people whose sight is partially impaired may create additional problems in movement and orientation, although aggressive patterns and tones may turn out to be tiring. Attention must be drawn to floors which ought to have an even and non-slippery surface on which any level or function changes should be highlighted in contrast colors. For this purpose, also special bumps are used that can be sensed by the blind with a cane, however the material and form of those marks must not pose additional dangers, for example tripping or slipping. Stairs and slopes should have rugged surfaces in order to ensure better adhesion and must be protected with balustrades from both sides. Each country has its own set of rules concerning these elements; however, there is a common need for balustrades to have easy-grasping handles which are extended towards movement surfaces by $30 \mathrm{~cm}$. Also spatial maps of a hotel and its recreation surroundings may be used which will help the guest to get to know a new space. [5, p. 27, 6, p. 40, 4, pp. 46, 2, pp. 21-22, 53-54] The most comfortable solutions of vertical communication are elevators and in a hotel they may be installed in spite of a number of floors because they will serve all guests and luggage transportation. It is important to keep operating tables (preferably in a horizontal 
position) on an accessible height which nowadays seems to be a standard. Another popular solution is also the use of the public address system (PA) in elevators and other characteristic orientation points which helps blind people and partially sighted to navigate. The recommended [2, p. 63] minimum measurements for a hotel elevator adjusted for the disabled is $140 \times 140 \mathrm{~cm}$ with doors not smaller than $90 \mathrm{~cm}$, additional handles and symbols in Braille.

\subsection{Measurement Recommendations}

Wheelchairs have a number of measurements depending on their type and driving gear. The typical manual utility dimensions vary within width of $60-75 \mathrm{~cm}$ (i.e. $31 \mathrm{~cm}$ in a closed position), length $78-83 \mathrm{~cm}$ with sitting of $35-52 \mathrm{~cm}$ of width with the main wheel diameter at around $60 \mathrm{~cm}$. For electrical carts and scooters used usually for exteriors these data are: width $58-72 \mathrm{~cm}$, length $94-122 \mathrm{~cm}$ with turn radius about 70$80 \mathrm{~cm}$. According to ISO standards these data are as follows: width $70 \mathrm{~cm}$, length 120 $\mathrm{cm}$ which seems to be average and can be taken into consideration as typical. [4, p. $51,8-11]$. Width of the minimum passage for a person: with a cane or balcony -70 $\mathrm{cm}$, with two crutches $-80-90 \mathrm{~cm}$ or $68-96 \mathrm{~cm}$ (depending on a literature source), on a wheelchair $70-85 \mathrm{~cm}$, with a guide-dog: $75-80 \mathrm{~cm}$, with a white cane: $85-90 \mathrm{~cm}$ (175-185 cm in longitudinal section), $90 \mathrm{~cm}$ - through the door, for two people: on a wheelchair with another person beside - 1,50 or 1,60 m (depending on a literature source). The minimum standard corridor width vary depending on a country from 105 to $150 \mathrm{~cm}$, in Poland $1,20 \mathrm{~cm}$ and $180 \mathrm{~cm}$ for two lanes. The minimum working space for an operator sitting in a wheelchair has $80 \mathrm{~cm}$ of width, $60 \mathrm{~cm}$ of depth and minimum 1,2 $\mathrm{m}$ of depth for overall space (longitudinal section) - desk with floor. The height of operation level $-80 \mathrm{~cm}$ and $1,10,1,30 \mathrm{~cm}$ for shelves that can be reached above the workspace. As far as a general vertical hand-reach range is concerned for a person on a wheelchair, it is from $40-150 \mathrm{~cm}$ or $65-150 \mathrm{~m}$ (depending on a literature source) and optimal for activities: $90-125 \mathrm{~cm}$, side reach $0-60 \mathrm{~cm}$ (80 cm maximum) and on a working plane about $65 \mathrm{~cm}$ (front, maximum $80 \mathrm{~cm}$ ) $-80 \mathrm{~cm}$ (side, maximum $90 \mathrm{~cm}$ ). A standard sight level of a person on a wheelchair was set on 1,25 m from the floor surface. The vertical reach-range for a person moving with the support of a cane, crutches or a balcony is up to $155 \mathrm{~cm}$, but a lower range varies at $50-65 \mathrm{~cm}$. [7, p. 39, 4, pp. 44-45, 50, 70, 2, pp. 31-32] It is important to note that the suggested dimensions are standardized and they will vary depending on each individual and what is particularly visible in a hotel situation, each nation and race will have different anthropometric features.

\subsection{Room Recommendations}

Apart from general guidelines, there are several additional rules that will help guests with disabilities spend quality time in a hotel. First of all, user-friendly materials should be employed, i.e. natural, biologically safe and not emitting harmful particles or radiation. Instead of classically opening doors, disabled people are more comfortable with using sliding systems that can be manually or automatically operated with the use of buttons, touch sensors or photocells. [6, p. 40] The requirements prepared for 
residential architecture assume that for one elderly person room surface should amount to $20 \mathrm{~m}^{2}$, for two $22 \mathrm{~m}^{2}$ and for one disabled person this value ought to reach $23 \mathrm{~m}^{2}$. [6, p. 40] On the other hand, Jasiak, Swerda [4, p. 71] maintain that it should not be less than $16 \mathrm{~m}^{2}$. The operational space in front of the main facilities should have the size of $150 \times 150 \mathrm{~cm}$. Most disabled people use different wheelchairs for exteriors, i.e. electrical scooter and other types for interiors, therefore each individual room ought to have some free space for wheelchair parking which is minimum $4 \mathrm{~m}^{2}$. [6, p. 61] For people traveling with a guide-dog, a special place for an animal is required.

Windows and doors as well as sunshades must have opening handles on a reachable height. The same requirement refers to electrical plots, switches, touchpad, control panels and remote controls. This parameter is usually set on $80 \mathrm{~cm}$ or $85-110 \mathrm{~cm}$ (depending on a source) for door knobs and $90-110 \mathrm{~cm}$ for others. There must be an opportunity to turn off and on all the appliances and lights from the bed position. The arrangement of furniture, especially chairs, armchairs and beds should take into account ergonomics of changing positions from a wheelchair and enable approaching a given facility from at least one side. The minimum width of such a space is $80 \mathrm{~cm}$. Although wheeled utilities enable an easy space change and arrangement, there is a possibility to block them, therefore they will not move while sitting. Shelves, sections of wardrobes and hangers have to be placed on the aforementioned comfortable access ranges. The doors of furniture ought to be sliding and in the case of traditional ways of opening, a person should not be forced to drive too far away from the equipment. A supporting structure of utilities cannot interfere with movement based on a wheelchair, cane of crutches. The space under desks and tables must be minimum 0,8 $\mathrm{cm}$ wide and 0,67 high to allow driving underneath. The fittings with changeable, adjustable surface heights will allow different users to work comfortably. A phone connected with the reception and emergency numbers is necessary in each unit. [2, p. 53, 69, 73], [4, p. 156]

Each adjusted unit should be fitted with a private bathroom and an outdoor resting space to provide the disabled with maximum intimacy if necessary. The space for outdoor relaxation on a terrace, balcony, loggia or in a garden for each elderly or disabled person is minimum $4,5 \mathrm{~m}^{2}$. [6, p. 61] This sort of place allows a person to use it any time without any obligation to find an adjacent recreation green area in a foreign city. It is important to enable the bathroom usage without a need to ask for help of another person. The minimum standard dimensions of this room are as follows: width may vary depending on a country, i.e. $137-225 \mathrm{~cm}$ and length $150-300 \mathrm{~cm}$. [4, p. 70] It is very important that an alarm switch can be accessible from this place as well in order to call for help from the reception. This option may be used by all guests. In Hotel 'Puro' in Wroclaw a bathroom is hidden in a glass cabin automatically delicately lit in the night, so it is easily accessible at any time. This sort of solution helps to avoid disorientation caused by a stay in unusual conditions. Another popular solution that can be found, e.g. in 'Monopol' Hotel in Wroclaw is a shower that is leveled with the floor surface - formed in marble - and is accessible without having to overcome any thresholds. If a movable or still seat is installed on the wall, it must be on the same level as a wheelchair and must be connected to a set of handrails enabling easy change. If bathtubs are used, it is necessary that they are equipped with special railings and additional facilities protecting from slipping and permitting a sitting position. There are also several producers offering bathtubs opened from one side which makes 
entering and changing positions from a wheelchair more comfortable. They are deep with a barrel-like form and bathing takes place usually in a sitting position.

Measurement recommendations in reference to sinks/basins are as follows: width $60-70 \mathrm{~cm}$, depth $50-60 \mathrm{~cm}$, height of installation $80-90 \mathrm{~cm}$. Some producers offer basins of flat and wide shapes with a convex curvature in the middle of the front edge that enables supporting the body. A gentle inclination of the device prevents from wetting clothes which is possible while washing hands or the face in a sitting position. The handles on both sides help to pull towards and push back from the washbasin. If for aesthetical reasons a decorative blade is installed and the basin is placed in it, there must be an additional space underneath in order to enable driving under and the front edge should provide an easy grip for users like in Kipriotis Panorama Hotel \& Suites in Kos. It is recommended that for the needs of people on wheelchairs a mirror over a basin is inclined from the vertical position towards the user at about $10^{\circ}$. Shelves for cosmetics and toilet accessories should be installed at reachable heights providing a good observation angle and their shape should protect objects from falling. They can also be a part of the basin blade which seems to be a very comfortable solution. The toilet may be preferably accessible from the side with the minimum space of $115 \mathrm{~cm}$ between its side and the wall. It should be fixed on the compartment on the height of 50-54 cm and extended towards the front $75 \mathrm{~cm}$ from the back wall. $[4$, p. 72,2, p. $73,80,91]$

\subsection{Common Spaces and Leisure Activities}

All food courts, bars, restaurants, cafes should ensure easy access for the disabled, which is not sufficiently respected in small coffee bars and clubs usually situated in basements. Tables and chairs must also follow the relevant regulations. In large rooms such as halls, conference halls and spacious restaurant lounges the problem of excessive reverberation time causes the main sound waves to fade and makes speech incomprehensible. For this kind of interiors, inductive loops supporting individual hearing aids are used that help to strengthen the original sound. For translations and guided tours, radio systems with individual headphones may be used. In this group also infrared systems can be employed. The seats in assembly halls should be arranged possibly close to the speaker and performed presentations because such an arrangement will provide a better view for people with sight disabilities as well as preferable loudness for those with hearing disorders. The depth of space for the disabled sitting in a row arrangement is $155 \mathrm{~cm}$. [2, pp. 23, 98] There is also a need for enabling access to hotel SPAs, sport zones, fitness centers, swimming pools and so on. If a lot of guests with special needs are expected to arrive in a hotel, it is advisable to equip a sport center with adjusted devices. The changing rooms should have separate cabins for people undressing in a sitting position (measurements $1,5 \mathrm{~m} \mathrm{x} \mathrm{1,9} \mathrm{m)}$ or lying position $(2,00 \times 2,20 \mathrm{~m})$ and showers which enable driving into cabins. Both areas must be equipped with handles and balustrades. In sport areas, wheelchairs designated for these zones should be used. This equipment needs the space not only for parking and storing, but also for cleaning and disinfection. For pools, special lifters or movable chairs are used that enable slow descending of a person into the water, however this sort of facility may be negatively perceived for psychological reasons. In this range, pools with movable bottoms that allow driving with a pool's wheelchair on 
them and then slow lowering into the water are recommended. In these areas, adjusted barriers and handles should be used enabling movement for people with disabilities and orientation disorders. Also anti-slipping floors are indispensible in these areas. [2, p. 110, 4, pp. 139-145]

\section{Case Study - References}

Field studies were conducted in Windmühle Seifhennersdorf, Germany. The complex of buildings of a training center (designed by Architekturbüro Gustavs + Lungwitz Dresden [12]) includes two hotels, restaurant and a regional house as well as workshops, all situated on a hill in a place of an old windmill. The entire site despite its varied landscape is adjusted to people with disabilities, especially for those moving on wheelchairs, i.e. with the use of slopes, footbridges, bridges and terraces made of stone, wood, granite paving or concrete. This diversification also comprises an interestingly shaped green area offering recreation, leisure and open-air games (e.g. terrain chess) and it is accessible for everyone.
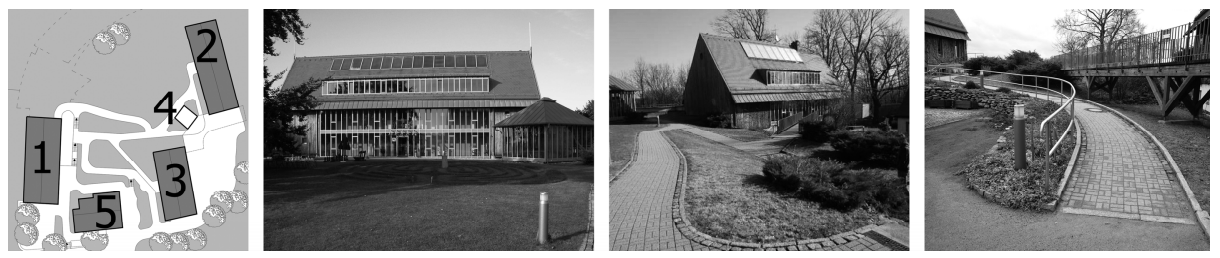

Fig. 1. Windmühle Seifhennersdorf - from the left: situation (site plan), large hotel, small hotel, adjusted terrain - wheelchair slope and bridge (on the plan: 1 - service building: restaurants, library, meeting halls; 2 - large hotel with rooms for the disabled; 3 - small hotel, with rooms for the disabled, 4 - elevator leading to the lower level with workshops 5 - regional house reception, meeting rooms [Elaborated on the basis of evacuation plans [13]).

Buildings have simple forms inspired by architecture of the region and historical object of the complex. Their shape harmonically blends in with the surroundings, which facilitates relaxation and creative activities that are held in workshops. Natural materials such as wood, ceramic and glass enable taking care of guests' health, with their colors that are toned but recognizable. The slope roofs referring to the local architecture were fitted with solar panels in order to gain renewable energy and keep air as clean as possible. Two hotels are comfortable to use and are relatively low - only two floors with wide corridors. Rooms for people with disabilities were situated only on the ground floor of the buildings on external sides of buildings in order to omit unnecessary movement and keep the way towards them straight and simple. The information placed near each entrance makes navigating through the structure even easier. 

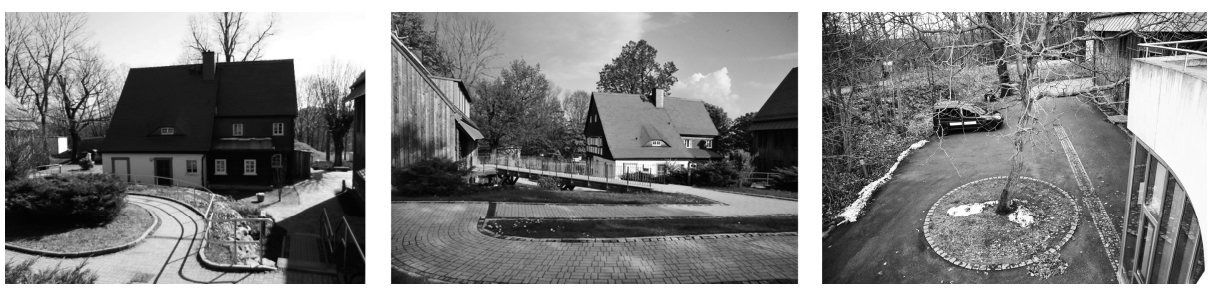

Fig. 2. Windmühle Seifhennersdorf - from the left: regional building with terrain adjustment, slopes and level (regional building in the background), car access - rondo

Due to the fact that this scheme was duplicated in each object, guests can easily find their way each time they visit the complex. The corridors are well illuminated with daylight seeping through large windows located on one longer side. Contrasting but calm colors - yellow walls, blue floors, white ceilings - create a sort of frame for the passage designating the main directions for moving
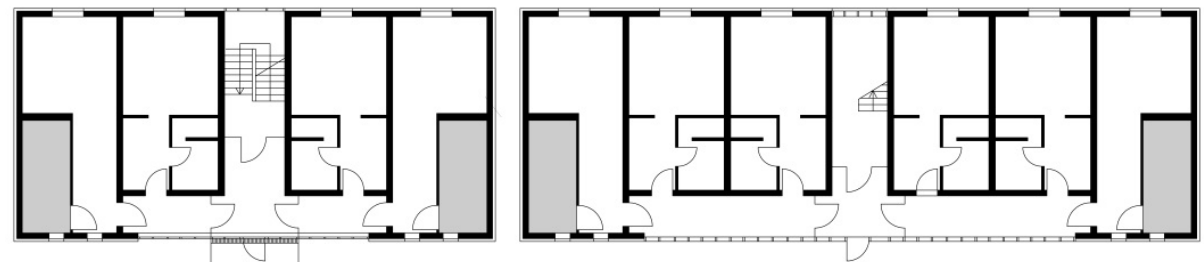

Fig. 3. Windmühle Seifhennersdorf - plans from the left: small hotel, large hotel (in gray adjusted bathrooms for disabled). (Elaborated on the basis of evacuation plans [13])
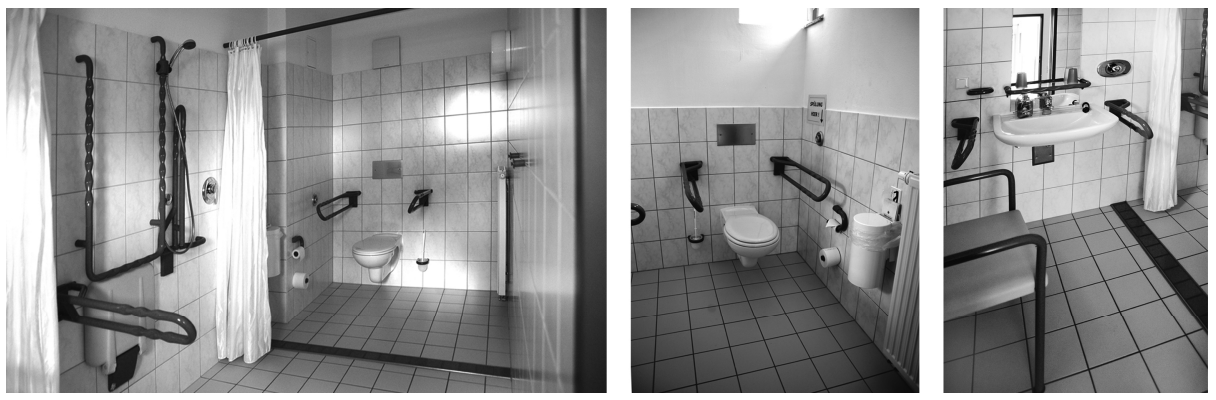

Fig. 4. Windmühle Seifhennersdorf - adjusted bathrooms for disabled users (from the left - in a large hotel, in a restaurant, details of a sink/basin installation)

In the adjusted rooms beds have been fitted with additional sides protecting from falling which can be also used as handles while sitting. Night cupboards are easy to reach, i.e. for turning on handy lighting. More furniture can be moved in order to arrange more free space in a room. Also an analysis of the building details has shown special thought put towards the proper adjustment of space. Also all elements which are important for orientation and moving such as handles, frames, balustrades as well as objects that can be hazardous like parts of the supporting construction were painted red in order to make them more visible. 

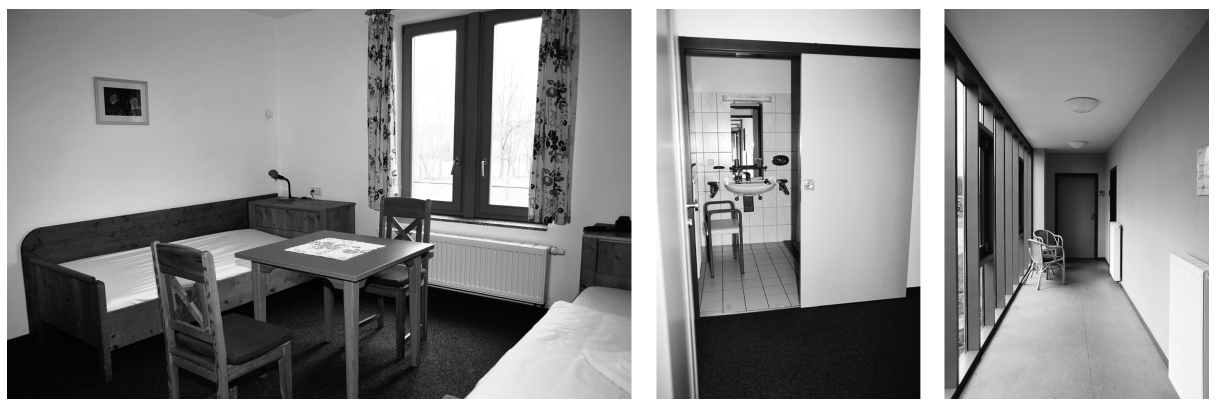

Fig. 5. Windmühle Seifhennersdorf - from the left: adjusted rooms, sliding doors to the bathroom, corridor

In the bathrooms sliding doors were installed and the passage was made wide. All facilities and equipment are placed in accessible spots for people on wheelchairs or with canes, furnished with basic and additional handles that have ribbed surfaces so they will never be slippery even when moist. The flush buttons were installed on side walls and dustbins are hung above the floor on a reachable height. An additional floor space for moving, turning, etc. provides disabled people with a comfortable environment.
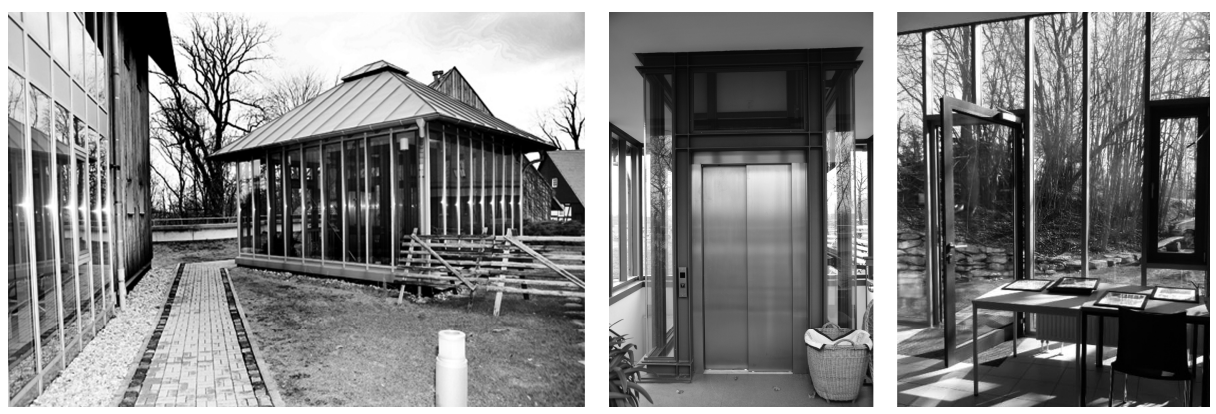

Fig. 6. Windmühle Seifhennersdorf - from the left: vertical communication building leading to workshops below, adjusted elevator, workshop's interior

\section{Conclusion}

Even a small disability can cause certain problems in movement, orientation as well as a physical and psychological heath status. This is why an important part of each hotel design should be their adjustment for special needs understood in a broad spectrum. As field and literature studies have shown, each element of a common building structure can cause hazards or be planned in an adjusted manner. Also some "designer" solutions (lack of balustrades, small differences in tones of colors, vast polished surfaces) which are very popular nowadays in hotels can be inaccessible for some groups of users. Although written sources show that a lot of knowledge has been gained, we can see that in practical terms these recommendations are not commonly 
used in buildings. Almost each modern Polish hotel contains an adjusted room; however, communication leading to it, its spatial plan of the main entrance vestibule, hall and reception may be confusing. Also level changes, slopes and stairs constitute architectural barriers as well as finishing materials of floors, while room furniture is sometimes not ergonomic at all and can be uncomfortable for users.

In the light of the aforementioned arguments, the main conclusion that can be drawn is that the issue of ergonomics in hotels should be studied further with a special focus on new technologies that employ natural materials which are safe for health and renewable, clean energy sources. A special emphasis ought to be placed on construction elements and environment parameters such as floors, stairs, slopes, level changes, elevators, natural and artificial lightings, colors and textures, furniture, orientation points (landmarks), balustrades and handles. Examples of good practice like the presented case study of Windmühle Seifhennersdorf complex must be broadly promoted in order to encourage architects and investors to focus closely on problems of people with disabilities and the elderly due to a great change and transformation in the European society structure in the nearest future.

\section{References}

1. Schwartz, L.: Wprowadzenie. In: Mayer-Bohe, W. (ed.) Budownictwo dla osób starszych i niepełnosprawnych (1998) (trans. Piliszek E., Arkady, Warszawa)

2. Błądek, Z.: Hotele bez barier. Przystosowanie do potrzeb osób niepełnosprawnych, Palladium Architekci Błądek-Manikowski, Poznań (2003)

3. National Census of Population and Housing 2011. Report of the results, Główny Urząd Statystyczny GUS /Polish Central Statistical Office, Zakład Wydawnictw Statystycznych, Warszawa (2012)

4. Jasiak, A., Swerda, D.: Ergonomia osób niepełnosprawnych, II ed., Wydawnictwo Politechniki Poznańskiej, Poznań (2009)s

5. Dettbarn-Reggentin, J.: Podstawy socjologiczne. In: Mayer-Bohe, W. (ed.) Budownictwo dla osób starszych i niepełnosprawnych (1998) (trans. Piliszek E., Arkady, Warszawa)

6. Mayer-Bohe, W.: Budownictwo dla osób starszych i niepełnosprawnych (1998) (trans. Piliszek E., Arkady, Warszawa)

7. Mayer-Bohe, T.: Podstawy budowlano-prawne. In: Mayer-Bohe, W. (ed.) Budownictwo dla osób starszych i niepełnosprawnych (1998) (trans. Piliszek E., Arkady, Warszawa)

8. http://www.gortomed.pl/wozki_inwalidzkie.php (access: February 10, 2013)

9. http://www.ortcare.pl/pages/elektryczne/spis.html (access: February 10, 2013)

10. http: //www. mobil-activ.pl (access: February 10, 2013)

11. http://www . acumobil.pl/rapido.html (access: February 10, 2013)

12. http: //www.ibhoffmann. de/170-0-Artikel.html (access: February 23, 2013)

13. Evacuation plans, maps of Windmühle Seifhennersdorf 